\title{
Comparison of Grey scale versus Doppler ultrasound to detect deep venous thrombosis in lower extremities.
}

\footnotetext{
1. Medical Imaging Doctor Lecturer

Allied Health Sciences, University of Lahore.

2. MBBS, MSDU, DMRD

Assistant Professor

Allied Health Sciences, University of Lahore.

3. Ph.D., MSDU (Ultrasound)

Assistant Professor

Allied Health Sciences, University of Lahore.

4. M.Phil., Ph.D (Biostatics)

Assistant Professor

Allied Health Sciences, University of Lahore.

5. Medical Imaging Doctor

Senior Lecturer

Allied Health Sciences, University of Lahore.

6. M.Phil., Ph.D (Ultrasound)

Senior Lecturer

Allied Health Sciences, University of Lahore.
}

Correspondence Address:

Dr. Javed Tauqir

Allied Health Sciences, University of

Lahore.

javedtaquir@gmail.com

Article received on:

28/12/2020

Accepted for publication:

04/02/2021

\section{INTRODUCTION}

The establishment of ablood clotinsidea deep vein is termed as the deep venous thrombosis (DVT). The Deep vein thrombosis (DVT)) is a possibly life threatening problem that is common in the injured. However, it can occur initially also during hospitalization. ${ }^{1}$ Screening and avoiding DVT during hospitalization have received an extensive consideration ${ }^{2}$ Deep venous thrombosis usually originates in the lower extremity veins, starting at the calf veins (distal veins). If it progresses, involve the popliteal, femoral and iliac system (proximal veins). The venous thrombosis of distal veins is asymptomatic while proximal veins are usually symptomatic. In the $80-90 \%$ cases, it may lead to a very serious condition called pulmonary embolism (PE). DVT and PE are together referred as venous thrombo-embolism (VTE). VTE is a significant contributor in the burden of worldwide sickness. In western societies, the incidence of DVT in the general population has been estimated to be $80-100 / 100,000$ annually, while in South Asia, 4-75/100,000. ${ }^{3}$ The commonest sign and manifestations of deep vein thrombosis are aches / painfulness, puffiness, warmness, discoloration or redness and surface veins distention, though nearly half of them have no symptoms. ${ }^{4}$ The idiopathic or unprovoked clot in deep veins occur spontaneously without a cause. ${ }^{5}$ Ultrasound is currently the first-line imaging assessment for DVT in organization with an experienced Sonologist in the light of accessibility, affordability, relative usability, nonexistence of ionizing radiation or contrast material, and high 
sensitivity and specificity. ${ }^{6}$ The color Doppler scanning now can deliver a fast and non-invasive supernumerary method of diagnosing DVT in the vein particularly in the lower extremity above the Calf. ${ }^{7}$ Acute deep vein thrombosis can be revealed as a defect within the venous lumen without color on color Doppler imaging. In an acute DVT, the lumen of the vein is enlarged; vein compressible and no augmentation is demonstrated. The nonocclusive DVT usually gives fewer symptoms. In chronic DVT, The vein is incompressible, narrow and irregular, which shows an echogenic thrombus attached to the venous walls with collateral growth. The chronic DVT continues to be longer than 10-14 days. The DVT which has no symptoms, however is diagnosed with screening only, is termed as asymptomatic or incidental.,9

\section{MATERIAL \& METHODS}

After the approval from ethical committee (MMUT02183001) of the University of Lahore and Shalimar Hospital Lahore, this research work was carried out during the period of 6 months from May to October 2020. This was a cross-sectional analytical study. Gray Scale and Doppler ultrasonography for the diagnosis of DVT was done by Toshiba (Xario) and Mindray (Z5) with a multi-hertz-/ linear frequency range from 7- 15 $\mathrm{MHz}$, and convex transducers with frequency range 3-6 MHz. Based on the clinical suspicion of deep vein thrombosis, 140 patients of both the genders and aging 20 to 90 years, from the Emergency Department of Shalimar Hospital Lahore, were referred for ultrasound examination. Age- wise, they were divided into 7 groups while gender-wise, into 2 (Male and Female) groups. For analyzing the frequency of DVT in the right/ left or both legs, the patients were divided in three groups. These patients were initially examined by Gray scale with compressibility test to screen out deep vein thrombosis (DVT). Then, Color and Spectral Doppler analyses were done to confirm the diagnosis with augmentation. Development of the collaterals was also observed in all the patients. MC Nemar test was applied to compare the findings of Gray Scale with Doppler Ultrasound. P-value $<0.05$ was taken as critical. The data of results were also summarized in the form of graphs, tables, charts and images.
Quantitative data were presented in the form of mean and standard deviation and qualitative data were be presented in the form of frequency and percentage. Statistical software for social sciences (SPSS version 22.0) was used for the analysis of the data.

\section{RESULTS}

The calculated sample size of this study was 140 at $95 \%$ level of significance and 5\% margin of error. According to the Descriptive Statistics of age, the minimum age was 20 years and maximum age was 87 years. Whereas the mean and standard deviation of age was 50.9286 and 18.29245 respectively. Analyzing age distribution, 140 patients (20-90 years) of the present study, were observed in 7 different age Groups (Table-I). They were: 16 ( $11.4 \%)$ patients in age Group 1 (20-30 years); 20 (14.28 \%) patients in Group 2 (31-40years); 19 (13.6 \%) patients in Group 3 (41-50 years); 40 (28.5\%) patients in Group 4 (5 I -60 years); 20 ( 14.\%) patients in Group 5 (6 1-70 years); 19 ( I 3.6\%) patients in Group 6 (7 1 -80 years) and only 6 (4.3\%) patients in Group 7 (8 $1-90$ years).

Under the limb involvement analysis, it was observed that in this study, 14 (10\%), 70 (50\%), and 56 (40\%) patients, had DVT on both legs. on left leg and on right leg respectively (TableII). Observing the gender discrimination, 95 $(67.9 \%) \& 45(32.1 \%)$ patients were female and male respectively (Table-III, Graph-1). On Gray scale ultrasound, in 120 (85\%) cases found having significantly increased blood vessel size, intraluminal echogenicity and loss of compressibility out of total 140 cases (Image-1 \& Graph-2). However, on Doppler, in 130 (92\%) cases significantly increased blood vessel size, intraluminal echogenicity, absence of blood flow and negative Augmentation effect were observed (Images-1 and Graph-2). According to analysis of collaterals, 84 (60\%) patients, $20(14 \%)$ and 36 (26\%) patients had developed large, small and no collaterals respectively. The derived statistical values regarding sensitivity, specificity, positive/ negative predictive value of the present study data are quoted in Table-IV. 


\begin{tabular}{|c|c|c|c|}
\hline $\begin{array}{c}\text { No. of } \\
\text { Group }\end{array}$ & $\begin{array}{c}\text { Age of Patients in } \\
\text { Years }\end{array}$ & \multicolumn{2}{|c|}{$\begin{array}{c}\text { Number \& \% Patients } \\
\text { Out of 140 Case }\end{array}$} \\
\hline 1 & $20-30$ & 16 & $11.4 \%$ \\
\hline 2 & $31-40$ & 20 & $14 \%$ \\
\hline 3 & $41-50$ & 19 & $13.6 \%$ \\
\hline 4 & $51-60$ & 40 & $28.5 \%$ \\
\hline 5 & $61-70$ & 20 & $14 \%$ \\
\hline 6 & $71-80$ & 19 & $13.6 \%$ \\
\hline 7 & $81-90$ & 6 & $4.3 \%$ \\
\hline
\end{tabular}

Table-I. Analysis of seven groups of 140 cases on different age.

\begin{tabular}{|l|c|c|}
\hline $\begin{array}{c}\text { Affected Limb } \\
\text { (Right/Left) }\end{array}$ & Frequency & Percent \\
\hline Bilateral & 14 & 10 \\
\hline Left & 70 & 50 \\
\hline Right & 56 & 40 \\
\hline Total & 140 & 1000 \\
\hline
\end{tabular}

Table-II. DVT affected limb analysis.

\begin{tabular}{|l|c|c|}
\multicolumn{1}{|c|}{ Gender } & Frequency & Percent \\
\hline Female & 95 & 67.9 \\
\hline Male & 45 & 32.1 \\
\hline Total & 140 & 100 \\
\hline
\end{tabular}

Table-III. DVT Gender analysis.

\begin{tabular}{|l|l|}
\hline \multicolumn{1}{|c|}{ Statistic } & Value \\
\hline Sensitivity & $87.88 \%$ \\
\hline Specificity & $70.73 \%$ \\
\hline Disease prevalence $\left(^{*}\right)$ & $70.71 \%$ \\
\hline Positive Predictive Value $\left(^{*}\right)$ & $87.88 \%$ \\
\hline Negative Predictive Value $\left(^{*}\right)$ & $70.73 \%$ \\
\hline Accuracy $\left(^{*}\right)$ & $82.86 \%$ \\
\hline \multicolumn{2}{|c|}{ Table-IV. Statistic values. } \\
\hline
\end{tabular}

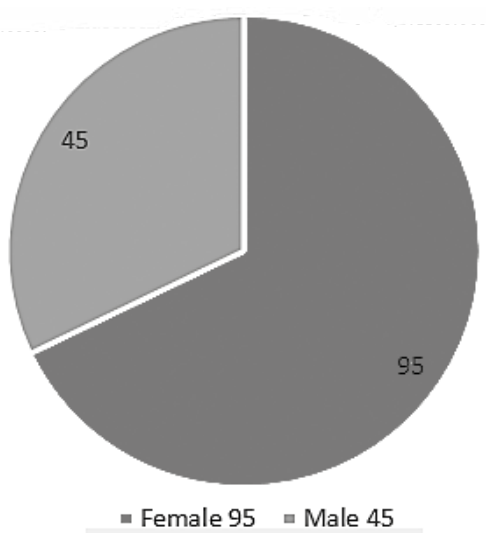

Gender Discrimination analysis

Graph-1

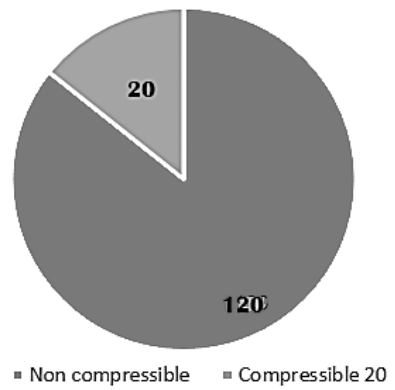

Graphically presented Gray Scale ultrasound analysis for compresibility Test

\section{Graph-2}

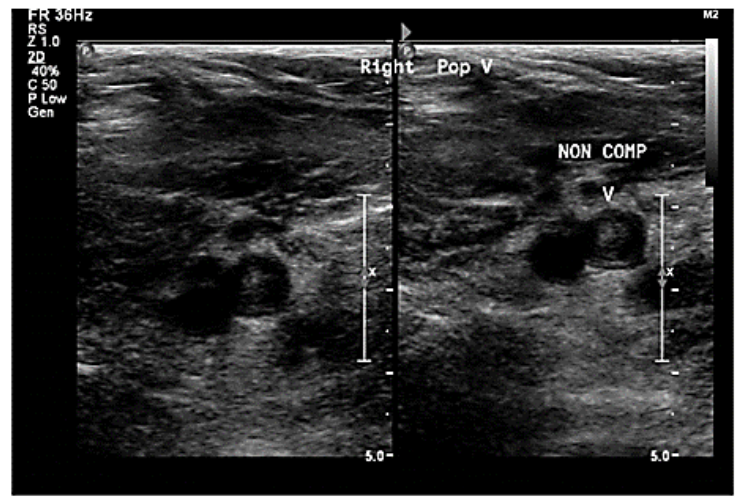

Gray Scale Transverse scan showing occluded Rt. Popliteal vein (DVT) with significantly enlarged size, intraluminal echogenicity and loss of compressibility

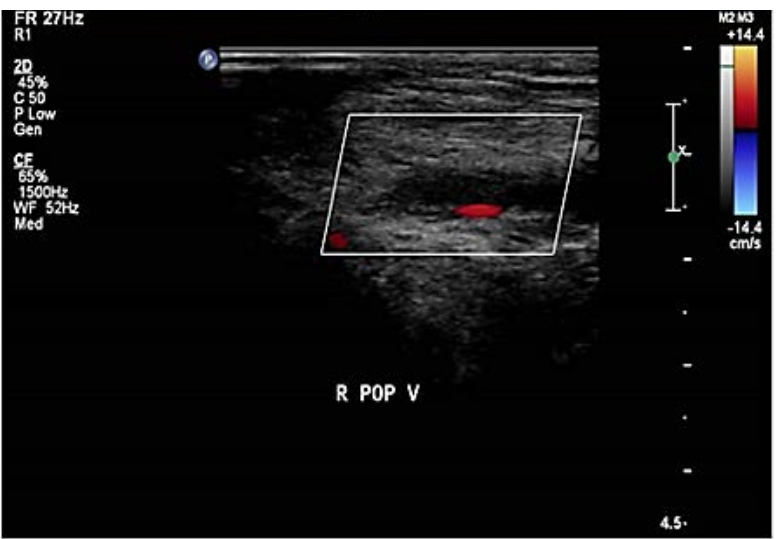

Sagittal scan showing occluded Rt. Popliteal Vein (DVT) with significantly increased Blood vessel size, intraluminal echogenicity, and absence of flow on color Doppler.

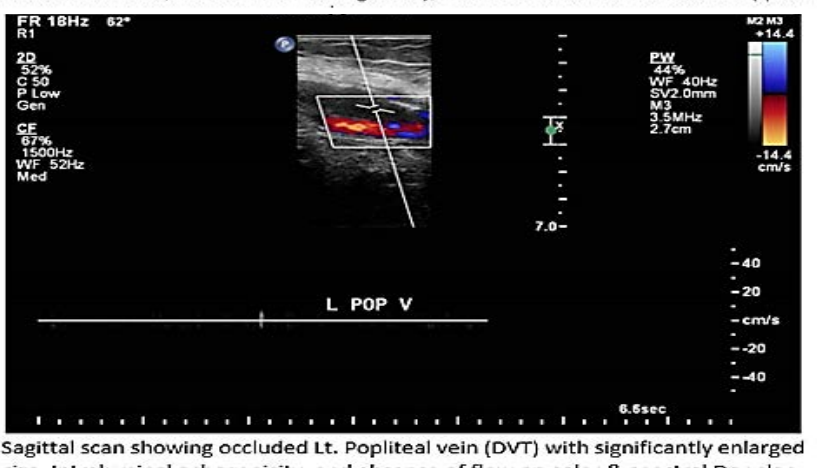
size, Intraluminal echogenicity, and absence of flow on color \& spectral Doppler 


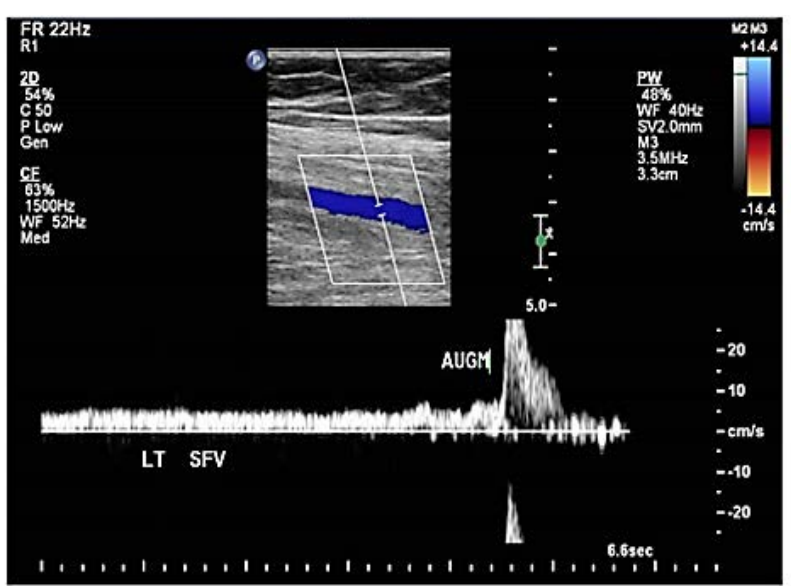

Colour \& spectral Sagittal scan showing a normal Augmentation response to squeezing the calf at Lt. superficial femoral vein

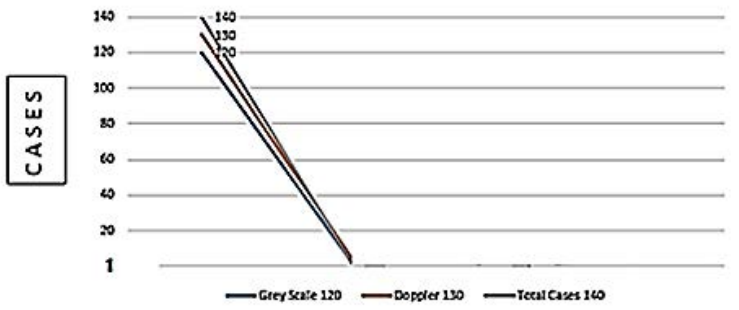

Graphically presented Gray Scale V/S Doppler DVT detection in lower extremity of 140 cases

Graph-3

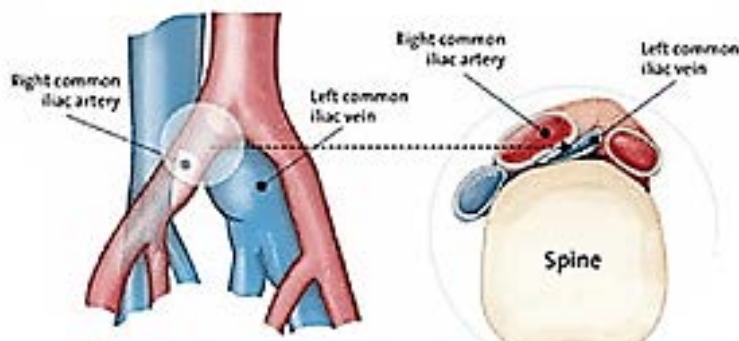

Compression of Vein by Artery against Spine seen from below

Figure-1

\section{DISCUSSION}

In the present study, the prevalence of DVT was more common in age group $51-60$ years. It indicates that the risk factors of DVT are strongly associated with fifth decade of age group. This finding of present study coincides with Engbers M (2010) "on his research "Venous thrombosis in elderly: incidence, Risk Factors and Risk Groups". ${ }^{10}$ The exact cause of higher incidence of DVT, associated with fifty to sixty years of age group, is still unknown.
In the present study, the DVT was found more in female patients (95 / 67.9\%) and less in males (45 / $32.1 \%$ ). This female dominating finding does not agree to the study by Sanjay M Kalandar findings: " $74 \%$ of the patients were males and $26 \%$ were females". ${ }^{11}$ However this finding of present study correlates well with the study conducted by Roosendaal FR et.al. Where higher incidence of DVT among females was found. The incidence of DVT is more in female population because estrogen and progesterone female sex hormones are associated with the initiation of DVT by forming thrombus in the blood vessels and first time it was explained by Rosendale FR et al. (2003) in his article "Estrogen, Progesterone and Thrombosis". ${ }^{12}$

It was observed in this study that DVT was seen more in the left leg as compared to right legs. This disparity might be related to anatomical compression of the left common iliac vein (LCIV) by the right common iliac artery as clarified by Thijs W et.al 2010 in research "Predominance of left-sided deep vein thrombosis and body weight" ${ }^{13}$ and Ashley B. et.al. (2018). ${ }^{16}$

In this study, the DVT detection by Doppler was more i.e. (92\%) as compared to $85 \%$ by Grey scale. This finding of present study coincides with that of Gi T et.al (2020). ${ }^{14}$ Similarly, it is supported also by Steve Goodacre et.al. (2005) in his Publication: "The value of clinical assessment in the diagnosis of deep venous thrombosis". ${ }^{15}$

\section{CONCLUSION}

The present study result concludes that Doppler may be used as gold standard to diagnose the DVT in the lower extremities. It concludes also that DVT detection accuracy by Doppler and Gray Scale ultrasound is minor i.e. 1:1.08. This minor difference encourages the radiology practitioners of periphery to screen DVT in lower extremities through gray scale ultrasound, if Doppler ultrasound is unavailable there. DVT was seen more in the left leg as compared to right legs. Most commonly DVT was seen in 51-60 years age group. The DVT was seen more in female participants.

Copyright@ 04 Feb, 2021. 


\section{REFERENCES}

1. Wang P-F, Li J-H, Fei C, Li Z, Ke C, Shang K, et al. Deep vein thrombosis in the uninjured limb in patients with lower extremity fractures: A retrospective study. BioMed Research International 2020; 2020.

2. Heit JA. Epidemiology of venous thromboembolism. Nature Reviews Cardiology 2015; 12(8):464-74.

3. Galanaud J-P, Arnoult AC, Sevestre M-A, Genty C, Bonaldi $M$, Guyard A, et al. Impact of anatomical location of lower limb venous thrombus on the risk of subsequent cancer. Thrombosis and haemostasis 2014; 112(12):1129-36.

4. Geersing G, Zuithoff N, Kearon C, Anderson D, Ten CateHoek $A$, Elf $J$, et al. Exclusion of deep vein thrombosis using the Wells rule in clinically important subgroups: Individual patient data meta-analysis. BMJ 2014; 348.

5. Meetoo D. Understanding and managing deep vein thrombosis. Nurse Prescribing 2013; 11(8):390-5.

6. Zierler BK. Ultrasonography and diagnosis of venous thromboembolism. Circulation 2004; 109(12_ suppl_1):I-9-I-14.

7. Kahn SR, Shapiro S, Wells PS, Rodger MA, Kovacs MJ, Anderson DR, et al. Compression stockings to prevent post-thrombotic syndrome: A randomized placebocontrolled trial. The Lancet 2014; 383(9920):880-8.

8. Chalikias G, Diehm N. Incidental versus symptomatic venous thrombosis in cancer: $A$ prospective observational study of $\mathbf{3 4 0}$ consecutive patients. Advances in Venous Arterial Thrombosis 2012; 1(4):175.
9. Iorio A, Kearon C, Filippucci E, Marcucci M, Macura A, Pengo V, et al. Risk of recurrence after a first episode of symptomatic venous thromboembolism provoked by a transient risk factor: A systematic review. Archives of internal medicine 2010; 170(19):1710-6.

10. Engbers M, van Hylckama Vlieg A, Rosendaal F. Venous thrombosis in the elderly: Incidence, risk factors and risk groups. Journal of Thrombosis and Haemostasis 2010; 8(10):2105-12.

11. Khaladkar SM, Thakkar DK, Shinde K, Thakkar DK, Shrotri H, Kulkarni VM. Deep vein thrombosis of the lower limbs: A retrospective analysis of doppler ultrasound findings. Medical Journal of Dr. DY Patil University 2014; 7(5):612.

12. Rosendaal F, Van Hylckama Vlieg A, Tanis B, Helmerhorst F. Estrogens, progestogens and thrombosis. Journal of Thrombosis and Haemostasis 2003; 1(7):1371-80.

13. Thijs W, Rabe K, Rosendaal F, Middeldorp S. Predominance of left $\square$ sided deep vein thrombosis and body weight. Journal of Thrombosis and Haemostasis 2010; 8(9):2083-4.

14. Gi T, Kuroiwa $Y$, Yamashita A, Mizutani $Y$, Asanuma $\mathrm{T}$, Miyati $\mathrm{T}$, et al. High signal intensity on diffusionweighted images reflects acute phase of deep vein thrombus. Thrombosis and haemostasis 2020; 120(10):1463.

15. Steve Goodacre, Alex J Sutton, Fiona C. Sampson meta-analysis: The value of clinical assessment in the diagnosis of deep venous thrombosis. Ann Intern Med. 2005 Jul 19; 143(2):129-39. doi: 10.7326/00034819-143-2-200507190-00012.

16. Ashley Barry, RVT, RDMS1. Sonography's role in the diagnosis of may-thurner syndrome. Journal of Diagnostic Medical Ssonography 2018, Vol. 34(1) 6570.

\begin{tabular}{|c|l|l|l|}
\hline \multicolumn{2}{|c|}{ AUTHORSHIP AND CONTRIBUTION DECLARATION } \\
\hline Sr. \# & Author(s) Full Name & Contribution to the paper & Author(s) Signature \\
\hline 1 & Javed Tauqir & Acquisition and Analysis. & \\
\hline 2 & Anjum Tazeen & Rectification and reviewing. \\
\hline 3 & Syeda Khadija & Rectification and reviewing. & $\mid$ \\
\hline 5 & Mehreen Fatima & Interpretation of Data. \\
\hline 6 & Syed Yousaf Gilani & Interpretation of data. \\
\hline
\end{tabular}

